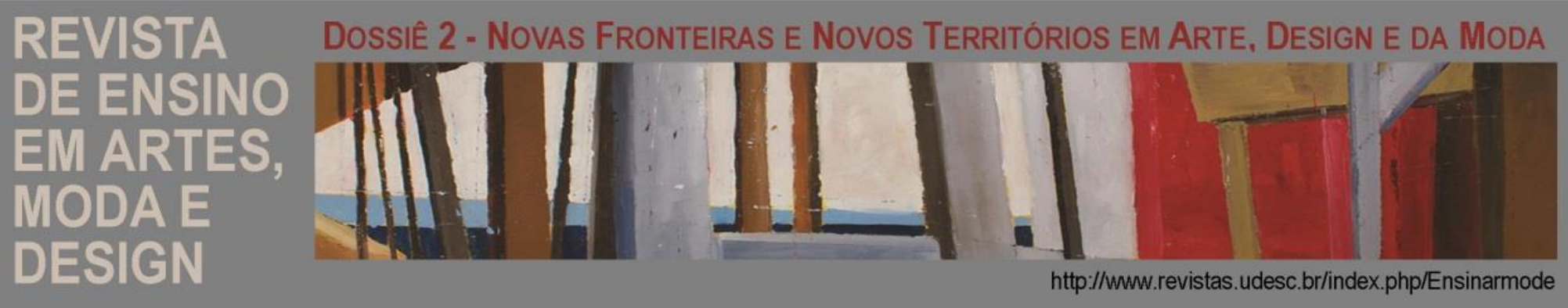

\title{
DESIGN FOR THE SENSITIVE: CONTEMPORARY POLITICS AND SOCIAL ACTION
}

Mônica Moura ${ }^{1}$

\begin{abstract}
Contemporary Design acts towards the possibilities and challenges of human comprehension in its complexity and the reading and analysis of this time, people and their ways of being in the world, possibilities, expressions, projects, products, objects, environments and services - material or immaterial - to give voice and expression to the different sensitivities and differentiated subjectivities (both designer and user) changing methods and highlighting the role of individual or collective authorship by expanding perceptions and diversities. Its purpose is to explore in contemporary design the universe of the sensitive on the way to political, social and citizenship action based on the awareness of current issues. In this sense, this text presents a brief historical resumption of the social issues in the field of design examining the constitution of new frontiers and territories in their relationship with society intermingling aesthetics, politics and the question of the sensitive. It takes Ranciere's "the share of the sensitive" as a reference and texts that underlie the issue of social responsibility of designers, and how this issue is being addressed today. The theoretical framework adopted includes the following authors: Manzini (2015), Rancière (2009), Weber (2008, 2010), Margolin (2006, 2004), Cooper (2005), Heller and Vienne Glaser (2003, 2013), Krippendorf (2000), Redig (1978, 1977), Papanek (1971). This text was developed from the results of exploratory research with a qualitative approach and adopts the following methodological steps: literature review, documentary research and case studies that guided the analyzes and syntheses presented.
\end{abstract}

Keywords: Design. Policy. Social Responsability.

\footnotetext{
${ }^{1} \mathrm{PhD}$ in Communication and Semiotics (PUC / SP) with postdoctoral studies in Contemporary Design (PUC / Rio), and Post Doctoral Internship (UMINHO / Portugal). Professor and Researcher at UNESP, FAAC, Bauru, working in the Design Department, Graduate Program in Design, Leader of the Research Group and Coordinator of the Research, Extension and Teaching Laboratory in Contemporary Design.

E-mail: monicamoura.design@gmail.com | Lattes http://lattes.cnpq.br/5034451123099716
} 


\section{INTRODUCTION}

This text is the result of a concern about the role of design today. Since often the design is (still) treated as something decorative or as a style build. However, in light of so many political and social problems that beset our world, other views and actions must be developed within contemporary design. This question led me to further research on the role of design in society by investigating the premises of this field of knowledge. In this way, this text aims to rescue the relations between design and politics; design in social transformation and design to the sensitive. The methodology adopted is of an exploratory and qualitative nature, comprising bibliographical and documentary research and case studies that guided the analyzes and syntheses carried out. The organization of the work is structured in the following parts: Frontiers and territories in contemporary design; The potential of design in social transformation; Design with social responsibility; Design as a political activity; Design for the sensitive; Contemporary design constituting social actions; Final considerations; References.

\section{DEVELOPMENT}

\subsection{Frontiers and territories in contemporary design}

The research I have developed on contemporary design points to several and different relationships with frontiers and territories, some new and others that are taken up under new visions, scope or clothing.

On the one hand, we have the fluidity or the breakdown between boundaries within the very field of design in its various areas and segments in a way that can be related to the total design², that is, a global thought that integrates the graphic, editorial, information, instructional, surface, digital, games, hypermedia, transmedia design; product design, fashion, jewelery, textiles, environments (interior

\footnotetext{
${ }^{2}$ This designation comes from the total work that was one of the objectives of the Bauhaus, as well as other previous and later movements that associated design, crafts and art. In 1963 a group of Dutch designers (Win Crouwel - typographer, Kramer Frieze - furniture designer and Benno Wissing graphic designer) founded the Total Design office, whose proposal was to apply the multifunctionality of their projects, applications and operations, developing and applying design for the same company / client in all needs and spans. Currently, Total Design, besides being a design office, is also a design consultancy. The term Total Design was adopted by several studios and labor market offices to designate the performance in all segments of the design in an integrated way (IN: MOURA, Mônica Cristina de. ) - Postgraduate Program in Communication and Semiotics, Pontifícia Universidade Católica de São Paulo, São Paulo).
} 
and exterior), ergonomics, usability, sustainability, inclusion, among other possibilities.

On the other hand, we have the constitution of new territories that takes place between the design and different areas of knowledge, such as design and art, architecture, medicine; design and anthropology, sociology, philosophy, economics, among other areas.

And yet, we have the constitution of new frontiers and territories from the association of the design field and new approaches from emerging themes or that are resumed and are gaining prominence and importance in contemporary society, such as design and politics, emotion, memory, feminism, crime, body, gastronomy, crafts, experience, technology, open technology, social design, social innovation, design with social responsibility, among other approaches.

As a synthesis of these aspects we will adopt the following designations: "design with" - association of the frontiers within the field itself or "design and" constitution of new territories, frontiers, approaches. Yet these 'design with' and 'design and' associations only indicate something already expected of the design discipline which main characteristic is centered on interdisciplinarity, transversality and transdisciplinary possibilities. The following diagrams present a summary of the aspects covered.

Diagram 1 -Design With: New Frontiers and Interdisciplinarities

\section{Design with}

Design as a

Field of Knowledge establishing new frontiers with the segments of its

own field within the meaning of Total Design

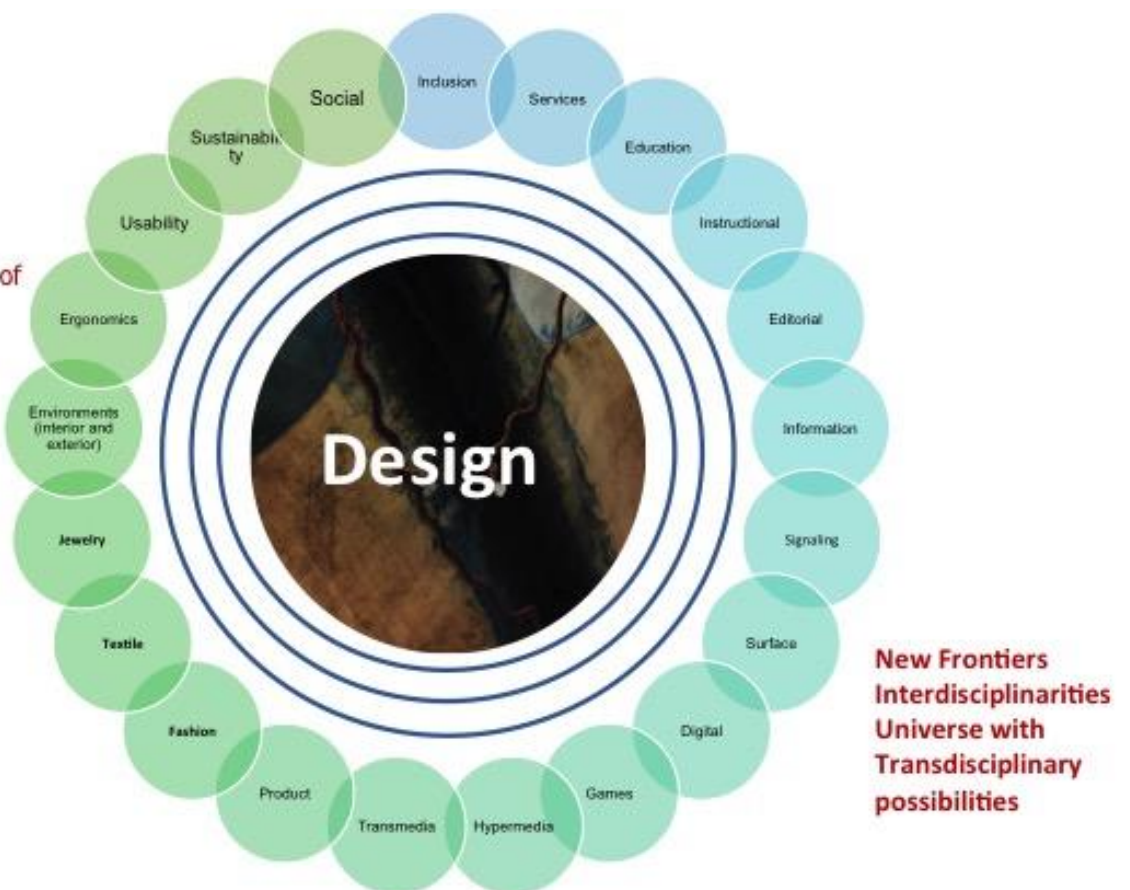

Source: Author, 2018. 


\section{Diagram 2 - Design And: Transdisciplinarities}
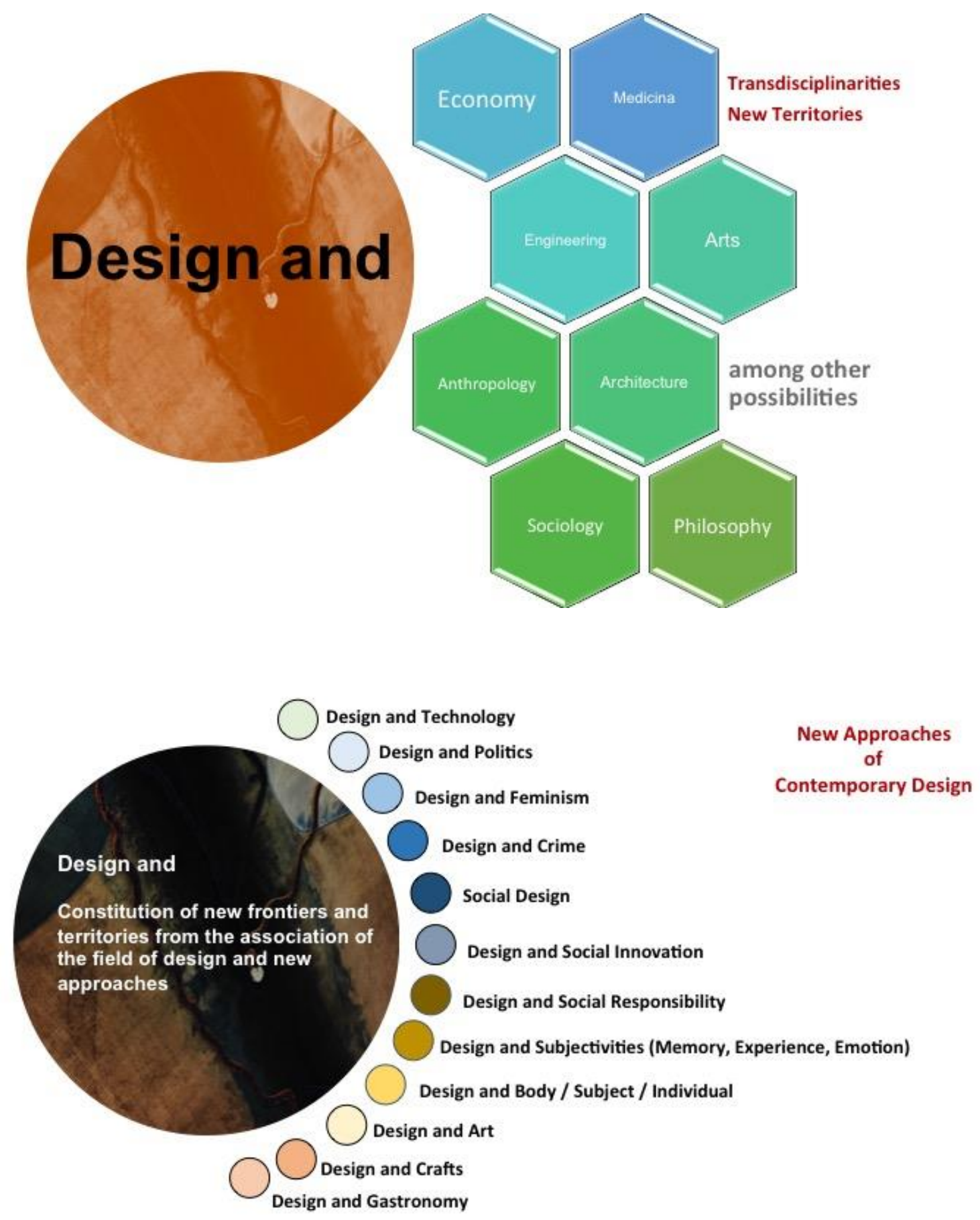

Source: Author, 2018.

Interdisciplinarity, transversality and transdisciplinary possibilities were amplified in contemporary times, but they have taken place in the history of design since the creation of the English movement Arts and Crafts in 1861, and also of a great part of the movements and schools that came later, in which the first traces of 
dialogue, of moving between different areas, segments, frontiers and territories were already established. We must also remember that the Arts and Crafts had a great influence on the pioneers of the modern movement and had as its fundamental proposition the fact that design could and should be a democratic tool for social change. The application of design to society through actions, changes, collaboration and the political exercise of citizenship is our main focus in this text and essential condition for the education and training of the contemporary subject, especially in the fields considered as creative and innovative.

Therefore, when dealing with new frontiers and territories we must take into account that some of the basic aspects of design are taken up nowadays. That is, when the initial ideas are launched they are not always applied immediately, because they lack deepening, or an awareness or even a demand that is built over time. In this sense, we have the social issue in design or the so-called social design, or, as more recently it comes to be treated, design with social responsibility

\subsubsection{The potential of Design in social transformation}

From historical design movements the concern and focus on society or social actions were indicated, as we saw earlier in relation to the Arts and Crafts. Modern movements have also brought this concern, yet which has been forgotten or relegated to the background by modern industrial production, functionalism and capitalism. And, nowadays, in light of the society of spectacle and consumption with outdated limits, the social theme in design is resumed, although it has been echoing since the 1960s, when the thought of design for society or of design acting on social changes gains body from the texts by Victor Papanek (1971). These texts expounded and criticized the reality of design at that time that was only about consumerism and profit, and the professional designers, for stimulating the growing manufacture of many products that did not work properly and inciting consumption without conscience and without thinking about future possibilities. From there Papanek questions, provokes and summons the designers to become aware of their role related to the social and the sensitive. And he said:

Design must be responsible to the ecology and responsible to society, must be revolutionary and radical (must return to its foundations) in the most exact sense of the word. It should be dedicated to the principle of the minimum effort of nature, that is, a minimum inventory oriented towards maximum diversity, in other words, to maximize the use of a minimum. What means to consume less, to use things for a longer time, to recycle the materials [...] the ideas, the broad general, non-specialized and interactive visions of a 
team that the designer can bring to the world, now must be combined with a sense of responsibility. There are many fields in which the designer needs to learn to "desdesign". Perhaps, in this way, we will still be able to "survive through design" "(Papanek, 1971, p.307, own translation).

Victor Papanek develops his critical thinking from his work Design for the Real World, highlighting the issue of social in design through a critical and intercultural approach and clarifying the designer's responsibility to society. For him, design was an innovative practice capable of exploiting the potential of transforming societies and improving human well-being, thus foreshadowing inclusive approaches in tune with today's contemporary design.

On the other hand, Rachel Cooper from the University of Salford emphasizes that the social design was constituted historically from the 1960s, when

\begin{abstract}
designers began to actively consider the broader implications of design for society. Several approaches have emerged, including green design and consumerism, responsible design and ethical consumption, eco design and sustainability, as well as feminist design. In the 1970s, designers were encouraged to abandon "design for profit" in favor of a more supportive approach, led mainly by Victor Papanek. In the 1980s and 1990s, issues of profit and ethics, as well as other market-oriented approaches emerged, such as the "green consumer" and "ethical investment." The purchase of socially responsible and "ethical" products and services was facilitated by the dissemination of research in the field of sustainability and publications oriented to consumer education. In addition, accessibility and inclusion have also been viewed with great interest by the design. Recently, designers have turned their attention to issues related to crime (Cooper, 2005, 80, own translation).
\end{abstract}

In Brazil, Joaquim Redig in the late 1970s already indicated that one of the principles of design is based on the relation "Man - User - Needs and Society", and points out that social balance can become a reality from the satisfaction of primary material needs. And he writes about this:

In poor countries like ours where the majority of the population does not yet have the minimum material conditions necessary for their food, health, housing, clothing, education, and work, the basic purpose of design is to solve the problems posed by the primary needs of the population, both urban and rural, both in terms of equipment and information, working in all areas and for all functional and social layers, where it is necessary to use their knowledge. (In this case are included the projects where the financial profit is seen as a consequence of the social gain, not the inverse.)

For Brazilian design, considering man is seeking to improve the material conditions of the majority of the population, and the consequent elimination of social discrepancies. (At this point the designer must work with anthropologists, sociologists, and economists to study the behavior, needs, and conditions of a given area or population, and with marketers and communication technicians to learn the factors related to commercialization, and communication of the product) (Redig, 1977, p. 28, own translation).

Despite the distance of time, unfortunately, we can see that the reality has not changed, in some cases was disguised and, in many cases, worsened by the 
population increase, the neglect of public policies with a series of issues involving a decline in quality of life in this country.

In Brazil today, in addition to the already traditional problems and mismatches with education, health, safety and housing, we can verify that the country also presents the most serious and major setbacks in the area of human rights. One of the documents that exemplifies this issue is Human Rights Watch's annual report of 2017, which identifies situations of human rights violations, namely:

- Restriction on freedom of expression;

- Discrimination against LGBTQ + people;

- Retreats on the rights of people with disabilities;

- Increase in the elderly population without special care;

- Contemporary forms of slavery or in conditions analogous to slavery;

- Domestic violence and feminicide;

- Continued outbreaks of severe mosquito-borne diseases;

- Largest prison population in the world, with very limited possibilities of resocialization;

- Overpopulation of adolescents in socio-educational units;

- High numbers of civilians killed by the police;

- Unprotected policemen with restricted rights;

- Murders and intentional violent deaths;

- Assassinations for land conflicts;

- Vulnerable and economically excluded groups (indigenous, landless and rural workers);

- Continuous negligence of the authorities;

- Lack of awareness and social mobilization.

In other words, the last few years have marked social retrogression, the loss of workers' rights, the collapse of social programs, the increase of unemployment, the return of poverty and hunger.

Faced with this and other national and world realities (human displacements, refugees, stateless people, exponential growth of the richest and the poorest, among other important issues) with which we live today in various parts of the world, it is necessary to raise awareness of all innovative and creative areas, such as design, fashion, art, architecture, education, among others, to act in favor of 
society, minimizing and acting in solutions to social problems. In this case, we must consider Design with Social Responsibility as a new territory to be explored.

\subsubsection{Design with Social Responsibility}

In principle, all design should be social, but the relationship with production and capitalist market, high consumption and luxury, have separated design of its role in society in the search for better living conditions of the population, especially the less favored and also the so-called invisible ones.

Papanek's reflections in the 1960s were never completely forgotten and always bothered and questioned the designers. However they were brought back to the public with a publication launched in New York after the World Trade Center buildings attacks in September 11, 2001, which is the collection "Citizen Designer Perspectives on Design Responsibility" edited by Steven Heller and Véronique Vienne. This work addresses the views of established designers on social, professional and artistic responsibility and has helped to disseminate a way of naming the relationship between design and society in a comprehensive and realistic manner.

Steven Heller (2003) in the introduction of Citizen Designer points out the need for a critical stance on the attitude of designers in their professional performance and also as citizens, recalling Milton Glaser who stated: "Good design is good citizenship", that is, to do good design is a fundamental and indispensable issue for society and for culture; in this case, it refers to good design as an indispensable obligation that adds value to society, enhances cultural and social dynamics, and therefore design and citizenship must go hand in hand.

The Citizen Designer texts reflect on the contradictions and difficulties of the relationship between social responsibility and the performance for the professional and consumer market. Heller states that "a designer has to be professionally, culturally, and socially responsible for the impact of their designs on citizens" (Heller, Vienne, 2003, p.10, own translation).

McCoy (2003), in his article in the same work (Citizen Designer) criticizes American designers for their lack of socio-political-cultural involvement, stating that design is not a neutral and worthless process. She emphasizes the importance of raising the awareness of designers about their actions and the development of critical thinking, noting that their formation should include the challenges of work and 
projects related to social, cultural and political topics. For her, "Designers have to be good citizens and participate in building government and society. As designers, we can use our particular talents and abilities to encourage others to action and participation "(McCoy, 2003, p.15).

In 2004, Sylvia and Victor Margolin published an article in the extinct Magazine Design in Focus of the State University of Bahia, discussing and proposing a model for the social practice of design. And they remember that from the call of Papanek, many designers started to work and develop design programs for "social needs, needs of developing countries, special needs of the elderly, the poor and the physically disabled." However, there are many theoretical and practical models (methods, processes, management, marketing, semiotics, consumption) for market design, but no model for the needs and social practice of design, which includes knowledge about the structures, methods and objectives of social design. Furthermore, they also point out that no attention has been paid to changes in the education of designers, especially with regard to the development of projects for populations in need (2004, p. 43).

The proposal of a Social Model of Design Practice is developed by the Margolin based on a similar process, that of intervention used in the area of social service, where the domains on human functioning are observed: biological, psychological, cultural, social, natural and physical / spatial. However, the Margolin develop their proposal targeted to product design and, in this case, select the physical / space domain, which implies objects, buildings, streets, transport systems, among other possibilities.

The authors define as a starting point that the primary objective of social design is the "satisfaction of human needs and we refer to people with low income or people with special needs due to age, health or disability" (2004, 44, own translation).

The proposed Social Model of Design Practice comprises the following phases: Commitment, Evaluation, Planning, Implementation. We present in the following diagram the phases and correlated activities of this action model.

We emphasize that the indicative user / client can comprise a group or a community. 
Diagram 3 - Social Model of Design Practice by Silvia and Victor Margolin

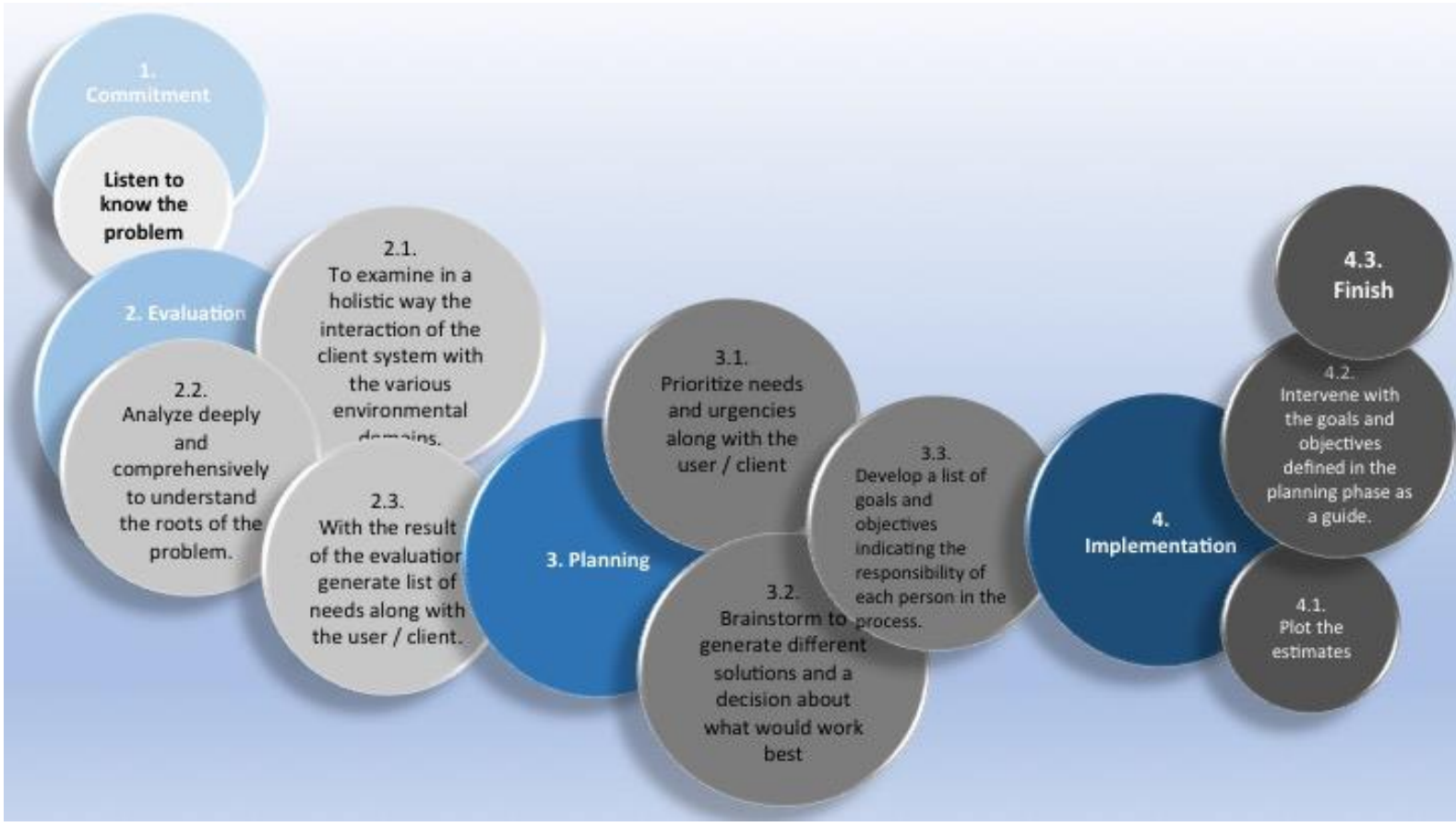

Source: Author, adapted from Social Model of Design Practice, Margolin, 2018

We can observe in this proposal of social action model for the area of design that the main to be developed, observed and highlighted is the sensitivity to listen to the other, the empathy put oneself in the other's shoes and the capacity for collaboration. In addition, involve the client / user / community to collaborate on the solutions that will be ideal for that person or group, and not always, as desired by the designer.

According to the Margolin (2004) the designer must act understanding the dynamics and the interaction between their "clients" and the environment where they live, a fact that determines a system. The whole process must be collaborative.

This model can be applied with the collaboration of different professionals, be they health, education, or public administration. The Margolin (2004) emphasize that the participation of processes and projects involving human services teams and designers is still open for exploration and that there are two main reasons for the lack of support for social design: the absence of a program of education and training in design schools and the lack of research that demonstrate how a designer can contribute to human well-being (2004, pp. 45-46).

Faced with the lack of research, the authors suggest a research agenda for social design: 
- What role can a designer play in a collaborative social intervention process? What is being done in this sense and what can be done?

- How can the public perception of design activity change in the sense of presenting an image of a socially responsible designer?

- How can agencies promoting social welfare and research projects gain a stronger perception of design as a socially responsible activity?

- What types of products meet the needs of vulnerable populations?

In another text called 'Citizen Designer', Victor Margolin (2006), questions the positioning of designers before society, stating that:

If the design community has the role of generating scenarios for social change, designers should seek to answer two questions: first, how to develop a set of reference values that can guide them in making judgments about how they would like the world to be, and secondly, how can designers learn to see beneath the deception of order and understand the true nature of the equipment, systems and situations with which (and for which) each one lives? (Margolin, 2006, p.145, own translation).

That is, Margolin is calling on the designers to assume their roles as critics and citizens and guides them to relate the products and services they develop with the following questions: the working conditions for their production, the materials used, the impacts on the use of resources and recycling, the effects on the individual sphere and the public sphere. Therefore, be aware of, promote and respect human, political, cultural, environmental, and social values and thus contribute to the "discourse on the quality of contemporary experience" (Margolin, 2005, 149, own translation).

This designer still refers to the pressure exerted by the consumption in a capitalist society and affirms that one must be aware of how much this pressure corrupts the public sphere. He also reminds us that we live in a world dominated by national and international corporations that transcend the power of the state and even the United Nations. But there are opposition movements carried out by the citizens in person or online, that is, the hope is in civil society acting together, in a collaborative way.

Margolin's text emphasizes that designers should look to the invisible, relate issues that seem disparate or contradictory, act in order to understand and act on emerging issues and causes, develop capacity for vision, positioning and political action. In his words:

I see the designer as having three possibilities of introducing their own talent into the culture. The first is through design, that is, doing things. The second 
is through a critical articulation of cultural conditions that elucidate the effect of design on society. And the third possibility is through the conduct of political engagement (Margolin, 2005, p. 150, own translation)

\subsubsection{Design as a political activity}

Regarding Margolin's political engagement, Cynthia Weber (2010) broadens this view and points to design as an essentially political activity, citing as an example the Casa Segura (Safe House) project by artist and designer Robert Ransick in 2007, which was a work developed from the problematic of the Mexican immigrants that cross the desert of Sonora, in the south of Arizona, United States. The Casa Segura was installed north of the Mexican border, involving landowners whose lands were crossed, in fact immigrants and the general public, to know the border issues of a region marked by traffic.

It is a conceptual project that contrasts existing conditions with new choices that positively transform how individuals on both sides of the divide engage with and perceive one another.

The project makes manifest the compassionate choices available to individuals who live within this highly charged border region. As an alternative to the further militarization of the border, Casa Segura offers a new method of engagement and free exchange. Shifting away from the abstract rhetoric of numbers, the project focuses on the anonymous-yet intimate-relationship between a property owner and the individual migrants walking their land. (Casa Segura, 2007, own emphasis, In: http://robertransick.com/casa-segura/)

Figure 1- Casa Segura, in Sonoran Desert, Arizona, EUA, 2007 and its lateral and frontal view
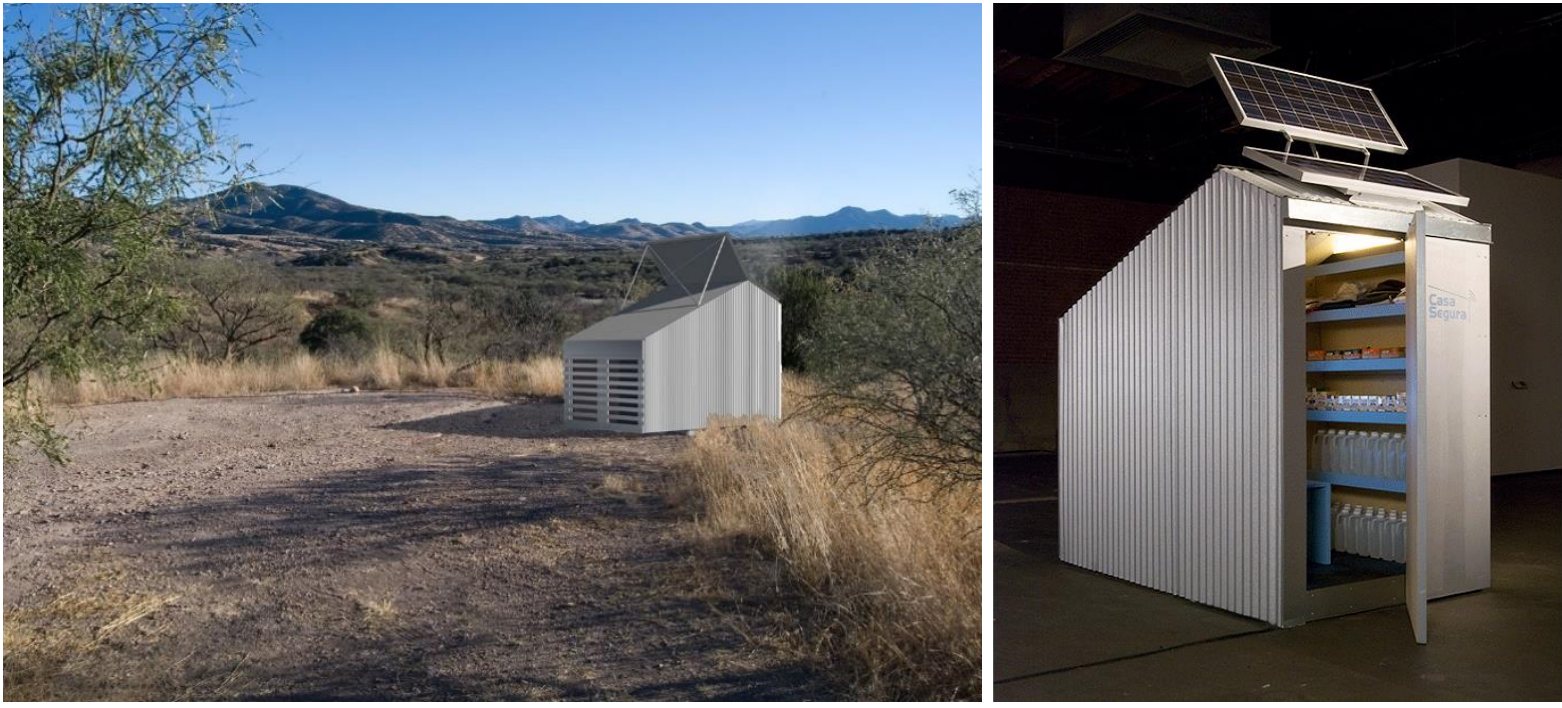

Source: http://robertransick.com/casa-segura/, 2007. 
The project consisted in putting a house, a temporary shelter, that is, a transitional space, with a small structure of solar energy to support the needy displaced immigrants - offering supplies like water, non-perishable food and an Internet-connected computer, to share stories or something creative about themselves and their journey with the landowner and with interested people. This process had as technological support a simple interface with touch screen in which the immigrants could draw, write messages or make a pictogram from a set of ready graphic icons ${ }^{3}$. The images and texts created were uploaded automatically to Casa Segura, a bilingual website that is a public space for viewing messages created by immigrants and also an access point for immigration resources and the borders of the southwestern United States.

Figure 2 - Inside Views of Robert Transick's Casa Segura, 2007.

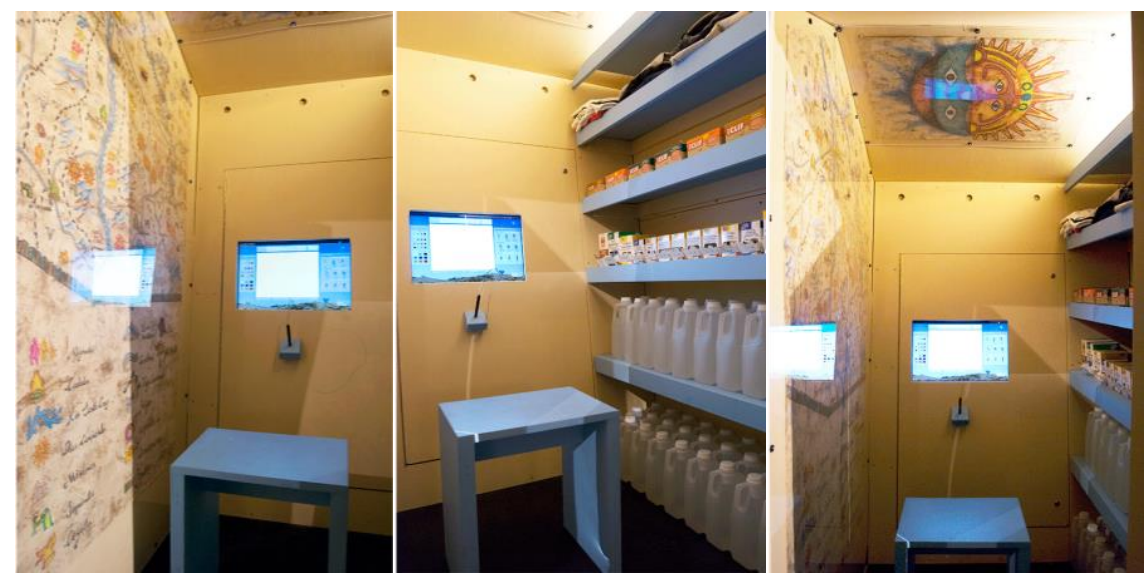

Source: http://robertransick.com/casa-segura/

The purpose of the proposal was:

a) to reduce the number of deaths by hunger and thirst of those who risk themselves in the crossing of the desert;

b) protect the properties of land invasion; and,

c) promote the recognition of the distinct realities between the two groups.

The designer responsible for the Casa Segura project was aware that the proposal would not be able to solve the complex set of issues that circulate around the border, illegal immigration and humanitarian efforts, however, acted to provide new opportunities for individual action, understanding, creative, communicative exchange and dialogue.

\footnotetext{
${ }^{3}$ The icons are representative symbols of Mexican culture, geography, myths and beliefs, were created in collaboration with Alberto Morackis and Guadalupe Serrano of Yonke Public Art in Nogales, Mexico.
} 
Weber (2003) points out that this project represented and exemplified an action and a work of design and citizenship, although not even mentioning the word citizenship in its scope. The action understood the society as a place of negotiation for problems created between the State and the subjects involved in the current issues, such as, human displacements. The author states that "the project allowed people to redesign alternative forms of citizen / non-citizen engagement, human, non-aggressive, sustained, and mutually interested" (Weber, 2010, p.12, own translation).

Another way of acting for the social is the rescue of memories and the expression and enjoyment of feeling through the aesthetic. In this sense, the Contextile - Biennial of Contemporary Textile Art, in its third edition, in the year 2016, was held in Guimarães, Portugal. The purpose of this event is to have in textile the main reference element in research, reflection and artistic creation. In the agenda of multiple activities, we highlight in this text, that of Artistic Residencies with traditional companies and techniques of the region of Guimarães, such as jacquard, stamping and embroidery, thus rescuing and valuing the memory and population of the region and approaching the contemporary textile art industry from new and different experiences and approaches.

The exhibition took place in the House of Memory of Guimarães open to the public and with free access.

The artists selected were Elena Brebenel of Romania; Inguna Levsa from Latvia and, Sandra Heffernan from New Zealand.

Elena Brebenel developed her work, called Breathing Nature from the observation of the landscape and flora in northern Guimarães. From the relationship with biomimetics, she made records in observational drawings, then elaborated repetitive designs for stamping, applied natural pigments and different materials and processes, and structured her project as an installation constituted by panels in different directions that created spaces for the observer walk and interact with the work. The silk fabrics provided the transparency needed to visualize the panel overlays. 
Figure 3 - Breathing Nature, Textile Work, Elena Brebenel, 2016.

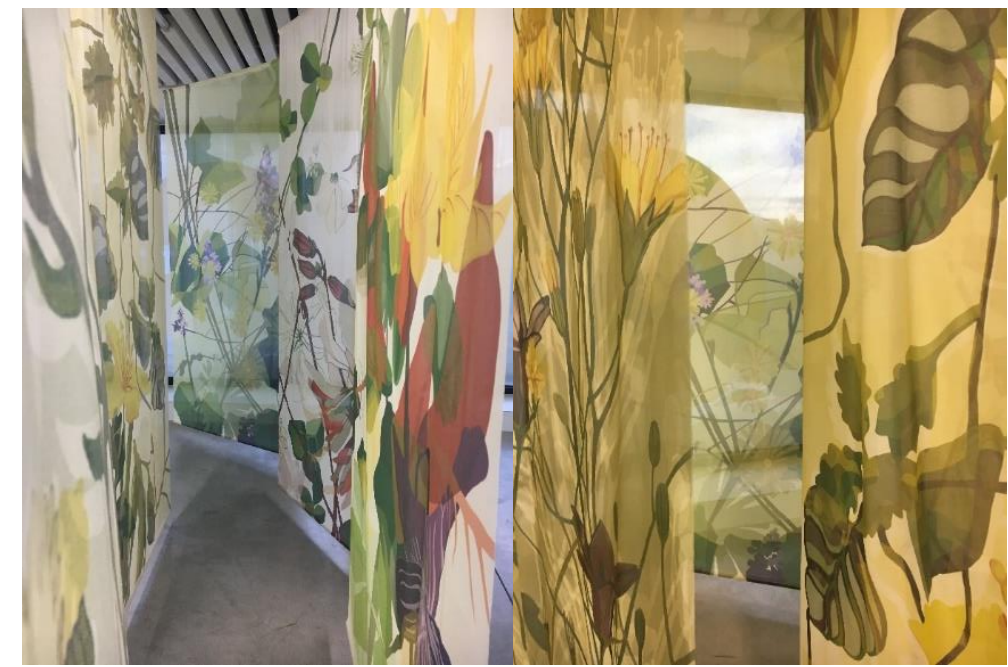

Source - Photos of the author, Contêxtil, House of Memory, Guimarães, Portugal, 2016.

Inguna Levsa worked with the question of memory and identity and from this motto created identities that do not exist, that is, they are imaginary and constructed from their references of real places and people of their proximity merged with random images that she finds in places she goes through. The artist developed three panels, being one graphic, one abstract and the other realistic. All made with the jacquard technique, made in cotton and linen.

Figure 4 - Identity as a Brand, Textile Works of Inguna Levsa, 2016.

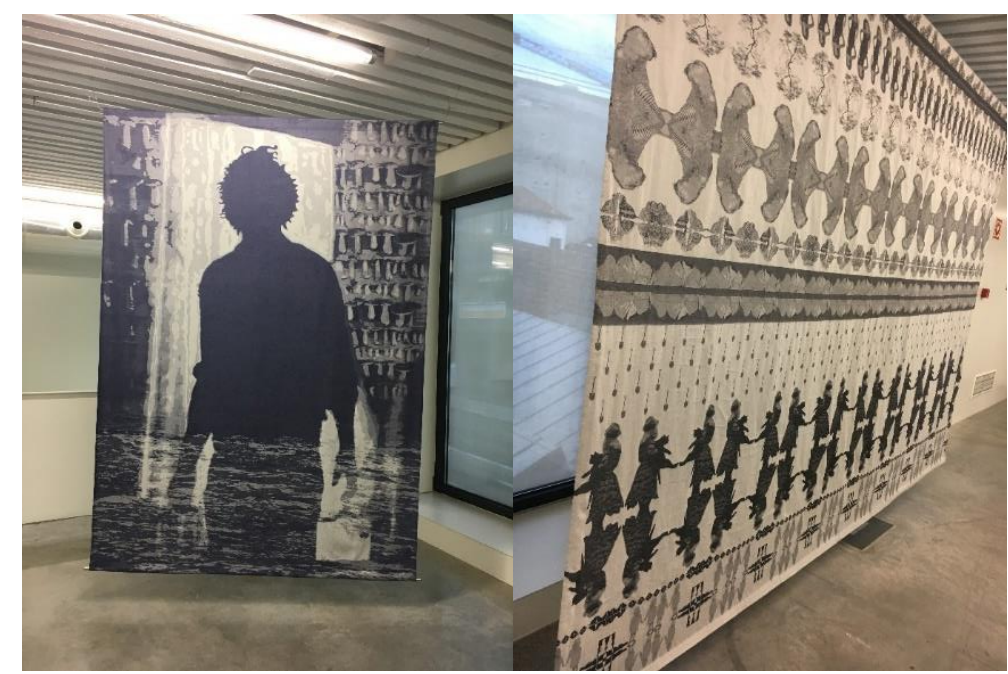

Source - Photos of the author, Contêxtil, House of Memory, Guimarães, Portugal, 2016 
Sandra Heffernan worked from the concept of antipode - the correlation with the other, the one that lives on the other side of the Earth or the planet - and constituted her work resuming and re-signifying the traditional embroideries of Guimarães, which were added the natural dye of walnut, indigo, weed and iron. The 14-meter-long piece was placed on different levels that refer to the configuration of the mountains and Serra da Estrela and also to the volumes, recesses and protrusions of the Earth.

Figure 5 - Through the Globe, Textile Works of Sandra Heffernan, 2016.

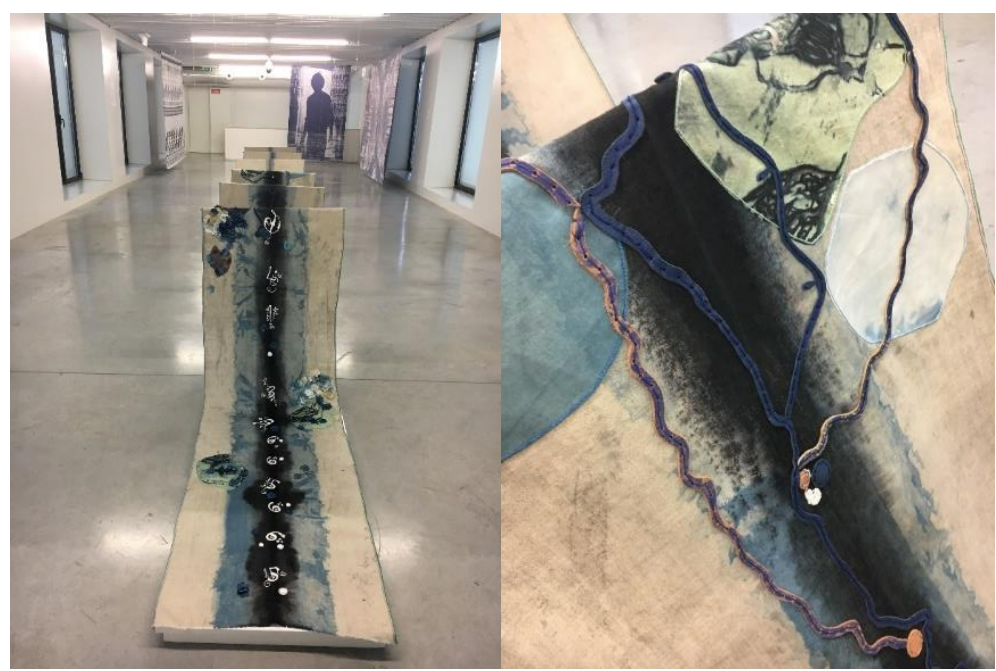

Source - Photos of the author, Contêxtil, House of Memory, Guimarães, Portugal, 2016

In the works presented above the sensitive was explored, in this case, associated with the reality seen by the foreign look, which constituted new landscapes and realities from the place, the identity, the human being and the place of the other, revealing the sense of humanity and the political role in valuing material and immaterial patrimony and memory, exploring the universe of the sensitive in the creation of the new.

\subsubsection{Design for the sensitive}

Contemporary Design goes beyond the new characteristics of form, materialities and immaterialities and the development of new methods that lead to multidimensional characteristics. There is a growing aspect that occurs through services and the search for solutions that can be found in the universe of the sensitive and these, in turn, can collaborate for the political and social action of the designers. 
The sensitive incorporates a knowledge that goes beyond the perception of reality, refers to the stimuli and emotions and the development of the capacities to receive sensations and to react to their stimuli, of judgment or evaluation of a given field, of sharing or of moving with other people's emotions. It is to have the capacity to observe, to understand and to put oneself in the place of the other, to live situations in adverse realities, to explore the sense of humanity, to seek the consciousness of the exercise of politics and of feeling.

We live in an environment populated by visual, sonorous and spatial stimuli, with excessive information and the imposition of frenetic and accelerated rhythms that can suppress our sensitivity and ability to perceive and exercise empathy, otherness and dialogue with the other. Studying and analyzing the contemporary issues associated with the universe of design, we focus on the possibilities of the exercise and needs of the contribution of this area to the human being, social subject, subject of the changes of our time and our society and we question about how to effectively contribute to the long-awaited quality of life. One of the ways presented is the acting of design, beyond materialities, in a universe of the sensitive.

The French philosopher Jacques Rancière defends social activism and questions the current world dominated by images. For him, politics is essentially aesthetic, as is art. In this sense, politics and art have a common origin, are founded on the world of the sensitive. For this reason, Rancière points out that politics is only democratic if it encourages the multiplicity of manifestations in the community. These issues led him to develop the concept of "the share of the sensitive," related to the formation of the political community based on the discordant encounter of individual perceptions. In his words:

I call the share of the sensitive the system of sensitive evidence that reveals at the same time the existence of a common and the clipping that define places and respective parts. A share of the sensitive fixes, therefore, at the same time, a shared common and unique parts. This distribution of parts and places is based on a sharing of spaces, times and types of activity that properly determines the way in which a common participant lends itself to participation and how both participate in this sharing (Rancière, 2009, p.15, own translation).

He points out that we have to think of aesthetics in a broad sense, as modes of perception and sensitivity, the way in which individuals and groups construct the world in an aesthetic process that creates the new, shifting the data of the problem. 
Taking the concept of "the share of the Sensitive", we can say that the action developed by someone, be them a creator or a designer, allows the involvement and action of the other (subject, social agent) on this something developed. The subject's action in sharing is political. In other words, it is created, something is developed that opens the possibility for people to share (share, divide, take part, participate) the common.

In this way, we can link the action of contemporary designers by observing and relating issues of society and the social subject through a proposal of action that can be constructed through different paths and bifurcations. Among these paths or possibilities we find:

- a proposal that comes from the conception of the designer to the society; or,

- a proposal that comes from the need or proposal of the social subjects; or,

- a proposal that is developed in a collaborative process integrating subjects that are not specialized in the field and the design professionals.

Manzini published in 2015, a study about the design and the role of the designers in the present time that is guided by the accelerated changes that we live in the contemporaneity. Faced with this reality, everyone (individuals, collectives, institutions, companies, communities, cities) should define, improve, plan, from a life project to complex projects, noting that often projects made by ordinary people generate unprecedented solutions that can meet simple goals or make major transformations. For Manzini (2015), we witness a wave of social innovations as these changes unfold and become consolidated processes of co-design, in which new solutions are suggested and new meanings are created. The author calls diffuse design, the one made by everyone (laymen) and specialized design the one made by design professionals. However, he highlights collaboration as an emerging form that can support significant social changes, from agriculture to food, from collaborative housing to digital and interactive platforms. And he points out that design professionals can facilitate the practice, implementation, diffusion, effectiveness and convergence for the realization of these projects and for the deployment in other projects. He also highlights that design for social innovation is the most comprehensive and dynamic field of action for experienced and inexperienced designers in the coming decades.

In tune with this thinking, Rancière points out that: 
the universes of perception no longer understand the same objects, nor the same subjects, no longer function in the same rules, then they establish unprecedented possibilities. It is not simply that revolutions fall from the sky, but the processes of emancipation that work are those that make people capable of inventing practices that did not yet exist "(Rancière, 2016, 8, own translation).

More recently, Milton Glaser (2013) states that we can not lose sight of the fact that design is a very embracing profession today. It relates to and incorporates utilitarian and informative products, requires both objective and measurable abilities, and can be a powerful means of personal expression, and is also an area that involves philosophical inquiry into beauty, truth, and reality, which can influence health and welfare of the general public, but can also be an instrument of change or social manipulation.

\subsubsection{Contemporary Design constituting social actions}

Another aspect that points to the growing concern of designers with the problems of contemporary society is the publication of works that deal with this subject, as well as the election of this theme in associations and entities representative of design.

The second edition of Citizen Designer: Perspectives on Design

Responsibility, to be released in 2018 , brings a series of essays that challenge and call designers to become aware of their role in society and the repercussion of their actions from the following questions: What does it mean to be a designer in the global consumer culture based on today's global corporations? How can a designer affect social or political change? Can design be more than just customer service? At what point should a designer take responsibility for the customer's actions? How to design a seductive packaging for fast food chains that promote obesity in children? How to design products that will be fabricated in miserable situations and locations under inhuman working conditions? Or weapons for defense departments? Or houses for smugglers or tobacco executives?

Professional associations begin to move in favor of citizen designer. So much that AIGA - The American Institute of Graphic Arts, based in New York, USA, has launched a campaign called "Are you a citizen designer?" in a program called Design for Democracy, whose proposal is:

Apply ideas and design tools to increase civic engagement. Independent, pragmatic, and committed to the public good, Design for Democracy collaborates with researchers, designers, and policy makers in public sector 
customer service, and fulfills AIGA's goal of "demonstrating the value of design by doing valuable things" (AIGA In: https://www.aiga.org/citizendesigner, own translation).

At the end of 2017, the ICO-D - International Council of Design, based in Montreal, Canada, presents itself as a non-governmental voice for design and as a non-profit, non-partisan network based on members acting in a creative way, facilitating dialogue between design platforms, including professional, educational and promotional categories, has designated design as a universal right: "-Everyone deserves to live in a well-designed world-" in the Montreal Design Statement. This document, which refers to the designers' obligations to address the social, economic, environmental and cultural impact of their work, has been signed by eighteen international organizations representing designers, architects, and landscapers, with more than 1 million professionals describing the potential of design to endure the important challenges humanity faces and to issue a joint call to action.

The Montreal Declaration of Design recognizes the unique value of design to address the complex issues of this century. It is a basis for collaboration between subscribing entities and an appeal to governments, the business sector, civil society and design professionals to harness the power of good design "(ICO-D in: http: //www.ico -d.org/2017/10/30/a-million-designersproclaim-all-people-deserve-to-live-in-a-well-designed-world.php, own translation).

Figure 6 - Promotion image of CDMX 2018

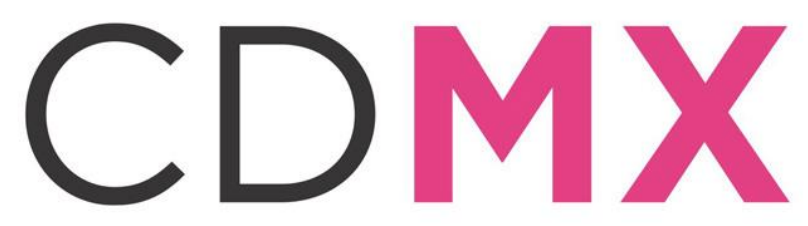

WORLD DESIGN CAPITAL 2018

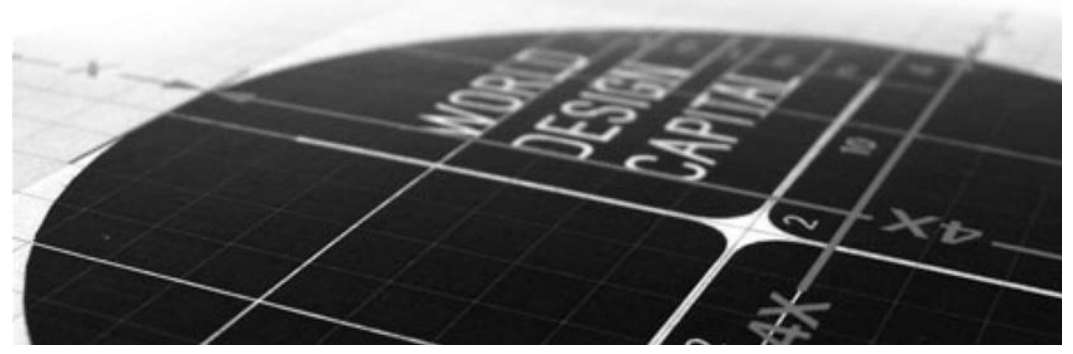

Source: http://wdccdmx2018.com/medium.html

In turn, WDO - World Design Organization, an international nongovernmental organization promoting the industrial design profession and headquartered in Montreal, Canada, has elected Mexico City as the Design Capital 2018, where the WDC CDMX 2018 event will take place, with the theme "Diseño socialmente responsable" (socially responsible design), which will address 
transversal axes involving issues related to Housing / Inhabitants, Mobility, City Identity, Environment, Public Space and Creative Economy from the following values:

1. Generate opportunities from the potential of design in terms of work, economy and restoration of the social fabric;

2. Restore dignity by highlighting the possibilities for improving the quality of life through design;

3. Preserve the valuable in a dialogue between the patrimonial, infrastructure and life in the public space;

4. Transform with respect proposing to rethink and build the future from the needs and narratives of our time.

These thoughts, texts and actions of designers, individually or collectively, or even through class entities, emphasize the relevance of design action beyond material production highlighting and revealing the design for the sensitive, understood here as the space of political action before the possibilities and challenges of understanding the human being in its complexity and the amplification of reality so that, from the knowledge built by study and research well grounded in the path of observation, reading and analysis of this time, the people and their ways of being in the world, explore the possibilities of action and inter-relationship that give voice and expression to different sensitivities and subjectivities (both designer and user), changing methods, sharing knowledge and expanding perceptions and diversities .

In a reality where we study and discuss the role of designers in face of social responsibility or actions, we can verify that Brazil has become a great field for applying the possibilities of design. However, are we really prepared for this? Do we want to see and face these situations? Do we really know how to deal with these problems, whether in the individual conception or in the collective, interdisciplinary, transversal action? Where are the projects that act on these lines of action? How are education and training in design, fashion, arts, and related fields developing this issue? Or how are they preparing themselves for student awareness on the way to professionalization? 


\section{FINAL CONSIDERATIONS}

As we have seen, the relationship between design and society is one of the central principles of design and has been pointed out in both historical and conceptual terms. Contemporary times have confronted us with challenges and catastrophic situations in many areas, and the tragic reality seems not only to impel, but also to re-raise awareness and responsibility for social, public, humanitarian and sustainable policies aimed at transforming and improving the quality of life. Given this scenario, it is not only the role of professionals in the creative and innovative areas that must be questioned. It is urgent to rethink the role and action of education and training. And one of the possibilities may be centered in the universe of the sensitive, that is, a more humanitarian design than a design connected to materiality and consumption, or rather, that the experience of designers with the universe of aesthetics and feeling is exploited by the politics, by sharing and to be applied in favor of the human being in a society, at least a little more fair.

However, we are still on the first steps of a long way to go through and explore, there is still much to contribute and learn from society and the universe of sensibility focused on contemporary and future life.

\section{REFERENCES}

CASA SEGURA. Projeto desenvolvido por Robert Ransick, 2007. Disponível em: http://www.casasegura.us/; http://robertransick.com/casa-segura/. Acesso em: 28 nov. 2017.

CDMX. Cidade do México Capital do Design. Disponível em: http://wdccdmx2018.com/medium.html; http://www.cdmx.gob.mx/vivecdmx/post/cdmx-capital-mundial-del-diseno-2018 . Acesso em: 25 jan. 2018, 18h35.

GLASER, M. O Estado Atual da Profissão. In: HELLER, S.; PETTIT, E. Design em Diálogo. São Paulo: Cosac Naify, 2013.

HELLER, S.; VIENNE, V. (Org.). Citizen Designer: Perspectives on Design Responsibility. Nova York: Allworth Press, 2003.

HUMAN RIGHTS WATCH. Brasil Eventos de 2016. Disponível em: https://www.hrw.org/pt/world-report/2018/country-chapters/313303._Acesso em: 27 jan. 2018, 23 h54.

INTERNATIONAL COUNCIL OF DESIGN. Disponível em: http://www.ico-d.org. Acesso em: 28 jan. 2018, 23h59.

MANZINI, E. Design, When Everebody Designs: Introduction to Design for Social Innovation. London: The MIT Press, 2015. 
MARGOLIN, V; MARGOLIN, S. Um Modelo Social de Design: questões de prática e pesquisa In: Revista Design em Foco, Salvador: EDUNEB, vol.1, n. 01, jul/dez, p. 43-48, 2004.

MARGOLIN, V. O Designer Cidadão In: Revista Design em Foco, Salvador: EDUNEB, v. III, n.2, jul/dez, p. 154-150, 2006.

McCOY, K. Good Citizenship: Design as a Social and Political Force. In: HELLER, S.; VIENNE, V. (Org.). Citizen Designer: Perspectives on Design Responsibility. Nova York: Allworth Press, 2003, p. 2-8.

MOURA, M. C. de. O Design de Hipermídia. São Paulo: 2003. Tese(Doutorado) Programa de Pós-Graduação em Comunicação e Semiótica, Pontifícia Universidade Católica de São Paulo, São Paulo.

OLIVEIRA, Caroline. 2017 foi ano de grave deterioração da situação dos direito humanos no Brasil. Disponível em: https://www.cartacapital.com.br/revista/987/2017-foi-ano-de-grave-deterioracao-dasituacao-dos-direitos-humanos-no-brasil. Acesso em: 19 jan. 2018, $14 \mathrm{~h} 10$.

RANCIĖRE, J. A Partilha do sensível. Estética e Política. São Paulo: Editora 34, 2009.

THE AMERICAN INSTITUTE OF GRAPHIC ARTS. Disponível em: https://www.aiga.org/. Acesso em: 12 jan. 2018, $15 \mathrm{~h} 30$.

WEBER, C. Introduction: Design and Citizenship. In: Citizenship Studies, v. 14, n. 1, p. 1-16, 2010.

2008

. Designing Safe Citizens. In: Citizenship Studies, v. 12, n. 2, p. 125- 142,

WORLD DESIGN ORGANIZATION. Disponível em: http://wdo.org/ ; http://wdo.org/programmes/wdc/wdcmexicocity2018/._Acesso em: 29 jan. 2018, $12 \mathrm{~h} 40$.

Recebido em: 13/02/2018

Aceito em: 03/06/2018 